\title{
Therapeutic modulation of the CD47-SIRP $\alpha$ axis in the pediatric tumor microenvironment: working up an appetite
}

\author{
Ajay Gupta ${ }^{1}$, Cenny Taslim², Brian P. Tullius ${ }^{1}$, Timothy P. Cripe ${ }^{1,2}$ \\ 'Division of Hematology, Oncology, Blood and Marrow Transplant, Nationwide Children's Hospital, Columbus, OH 43205, USA. \\ ${ }^{2}$ Center for Childhood Cancer and Blood Diseases, Nationwide Children's Hospital, Columbus, OH 43205, USA.
}

Correspondence to: Dr. Ajay Gupta, Division of Hematology, Oncology, Blood and Marrow Transplant, Nationwide Children's Hospital, 700 Children's Drive, Columbus, OH 43205, USA. E-mail: gupta.293@osu.edu

How to cite this article: Gupta A, Taslim C, Tullius BP, Cripe TP. Therapeutic modulation of the CD47-SIRP $\alpha$ axis in the pediatric tumor microenvironment: working up an appetite. Cancer Drug Resist 2020;3:550-62.

http://dx.doi.org/10.20517/cdr.2020.12

Received: 11 Feb 2020 First Decision: 18 Mar 2020 Revised: 25 Mar 2020 Accepted: 31 Mar 2020 Available online: 11 May 2020

Science Editor: Gerhard Hamilton Copy Editor: Jing-Wen Zhang Production Editor: Jing Yu

\begin{abstract}
Evasion of immune surveillance is one of the hallmarks of cancer. Although the adaptive immune system has been targeted via checkpoint inhibition, many patients do not sustain durable remissions due to the heterogeneity of the tumor microenvironment, so additional strategies are needed. The innate immune system has its own set of checkpoints, and tumors have co-opted this system by expressing surface receptors that inhibit phagocytosis. One of these receptors, CD47, also known as the "don't eat me" signal, has been found to be overexpressed by most cancer histologies and has been successfully targeted by antibodies blocking the receptor or its ligand, signal regulatory protein $\alpha(\mathrm{SIRP} \alpha)$. By enabling phagocytosis via antigen-presenting cells, interruption of CD47SIRP $\alpha$ binding leads to earlier downstream activation of the adaptive immune system. Recent and ongoing clinical trials are demonstrating the safety and efficacy of CD47 blockade in combination with monoclonal antibodies, chemotherapy, or checkpoint inhibitors for adult cancer histologies. The aim of this review is to highlight the current literature and research on CD47, provide an impetus for investigation of its blockade in pediatric cancer histologies, and provide a rationale for new combination therapies in these patients.
\end{abstract}

Keywords: CD47, SIRP $\alpha$, immunotherapy, tumor microenvironment, pediatric cancer, innate immune system, checkpoint inhibitor, phagocytosis

\footnotetext{
(@) ( $)$

(C) The Author(s) 2020. Open Access This article is licensed under a Creative Commons Attribution 4.0 International License (https://creativecommons.org/licenses/by/4.0/), which permits unrestricted use, sharing, adaptation, distribution and reproduction in any medium or format, for any purpose, even commercially, as long as you give appropriate credit to the original author(s) and the source, provide a link to the Creative Commons license, and indicate if changes were made.
} 


\section{INTRODUCTION}

Despite the recent successes of adaptive immunotherapy, a proportion of patients have not benefitted from durable remissions due to therapeutic resistance. The role of the innate immune system checkpoint blockade is only now being recognized. The combination of innate and adaptive immunotherapy has the potential to overcome known resistance mechanisms in cancer, such as CD47 overexpression.

CD47 is an immunoglobulin-like transmembrane protein displayed on the surface of nearly all normal, healthy cells in the body as a "don't eat me" signal to phagocytic cells. Conversely, aged or damaged cells and tumor cells often express the pro-phagocytic "eat me" ligands phosphatidylserine and calreticulin, with the balance of these opposing forces determining the activity of directly engaged phagocytic cells. The system is redundant, and a similar axis has been found between major histocompatibility complex class I expression on tumor cells and the inhibitory receptor leukocyte immunoglobulin-like receptor B1 mediating macrophage phagocytosis ${ }^{[1]}$. Moreover, cancer cells can release a mutated calreticulin that functions as an immunosuppressive ligand ${ }^{[2]}$. As with most mechanisms of immunosuppression utilized for healthy homeostasis, cancer cells often co-opt CD47 overexpression to escape innate immune surveillance by counteracting these signals ${ }^{[3]}$. CD47 binds to a myeloid and neuronal cell receptor called signal regulatory protein $\alpha(\operatorname{SIRP} \alpha)$, which initiates a signaling cascade within the bound phagocyte via immunoreceptor tyrosine-based inhibition motifs to inhibit immunoglobulin- or complement-induced efferocytosis of the tumor cell ${ }^{[3,4]}$.

The innate immune system is heavily influenced by modulation of CD47. In vitro studies have shown that the M1 (antitumor, inflammatory) macrophage's ability to ingest tumor cells is altered in a CD47-dependent manner; the same has not been found to be true for M2 (pro-tumor, immunosuppressive) macrophages, perhaps indicating the evolution of $\mathrm{CD} 47$ overexpression by cancer to evade the macrophages trying to attack it ${ }^{[5,6]}$. However, in the pro-tumoral niche, CD47 appears to have a symbiotic relationship with M2 macrophages. M2-conditioned medium induces CD47 expression in cancer cells, and M2 macrophages express more SIRP $\alpha$ and migrate to CD47+ cells faster, while CD47+ cancer cells invade more quickly in the presence of M2 macrophages ${ }^{[7]}$. Dendritic cells (DC) express increased SIRP $\alpha$ in cancer, inducing immune tolerance, decreasing DC survival and activation, and suppressing the cytotoxic T cell response ${ }^{[8]}$. Natural killer (NK) cells and neutrophils have also been shown to be affected by CD47 alteration ${ }^{[9-12]}$. We are beginning to understand the epigenetic mechanisms as well, and CD47 activation in disease appears to turn on ubiquitin-like anti-apoptotic proteins, turn off tumor suppressor $\mathrm{p} 16^{[13]}$, and affect targets associated with DNA methylation and histone modification ${ }^{[14]}$. As a therapeutic strategy, efforts are underway to block CD47-SIRP $\alpha$ binding and increase the innate immune recognition and phagocytosis of tumor cells. This blockade may subsequently lead to antigen presentation and adaptive T cell activation, which might then elicit further tumor destruction ${ }^{[15,16]}$.

CD47's biological role independent of direct binding to SIRP $\alpha$ is complex, and there is evidence that it can signal on its own or through independent ligands. The ligand also interacts with thrombospondin-1 (TSP-1), which can directly regulate angiogenesis, nitric oxide signaling, $\mathrm{T}$ cells, and cancer stem cell renewal ${ }^{[17,18]}$. When interacting with $\alpha_{v} \beta_{3}$ integrins, it modulates cell adhesion, phagocytosis, and migration ${ }^{[19]}$. It is also known to directly affect neural migration, axon extension, and T cell co-stimulation ${ }^{[16]}$. In fact, CD47 blockade accentuates $\mathrm{T}$ cell-based immunotherapies ${ }^{[20]}$. Because $\mathrm{CD} 47$ has roles independent of SIRP $\alpha$, investigators have successfully used the blockade of CD47 to affect additional interactions, including opsonization of tumor cells for antibody-dependent cellular cytotoxicity (ADCC) by the Fc receptor for IgG $(\mathrm{F} c \gamma \mathrm{R})$ on macrophages, neutrophils, and non-SIRP $\alpha$ expressing NK cells ${ }^{[17]}$. 


\section{EVIDENCE IN PATIENTS}

CD47 was first discovered on ovarian cancer cells as an overexpressed cell surface marker ${ }^{[21]}$. It is now known to be overexpressed on every tumor histology tested, including ovarian, breast, colon, bladder, and prostate cancers and glioblastoma, hepatocellular carcinoma, squamous cell carcinoma, and leukemias as well ${ }^{[4,16,22]}$. It may be especially well-expressed on cancer stem cells ${ }^{[23-25]}$. In adults, high tumor CD47 expression correlates with poor progression-free and overall survival in cancer patients, including adult patients with acute lymphoblastic leukemia (ALL), acute myeloid leukemia (AML), non-Hodgkin's lymphoma, Sézary syndrome, ovarian cancer, breast cancer, squamous cell carcinomas, gliomas, and astrocytomas ${ }^{[4,5,26-31]}$. Furthermore, poor response to chemotherapy (e.g., trastuzumab in breast cancer patients) may correlate with tumor cell CD47 expression ${ }^{[32]}$.

The data in pediatric cancers are sparse. CD47 expression was found to be an independent prognostic marker in children with $\mathrm{ALL}^{[29]}$. In support of this finding, anti-CD47 antibodies enhanced ALL phagocytosis in vitro and prevented ALL engraftment in a xenograft mouse model ${ }^{[29]}$. In pediatric AML, investigators found a relationship between SIRP $\alpha$ expression and AML FAB subtype or blast maturity, with the highest expression in the M4/M5 subsets; however, this did not correlate with outcome, and CD47 expression was uniform across samples ${ }^{[33]}$. In patients with osteosarcoma, increased CD47 mRNA expression and protein levels were found in tumor samples compared with paired normal tissue, which correlated with decreased progression-free and overall survival ${ }^{[3,35]}$. In support of this clinical observation, CD47 blockade appeared to decrease in vivo pulmonary metastatic formation in mouse xenograft models and increase tumor-associated macrophage (TAM) phagocytosis of osteosarcoma cells. In rhabdomyosarcoma, tissue samples for both alveolar and embryonal histologies showed high expression of CD47 and calreticulin ${ }^{[36]}$. Neuroblastoma patient samples were shown to have ubiquitous expression of CD47 and mouse xenograft models have demonstrated significant response to the blockade of CD47 and TSP- ${ }^{[37]}$. In childhood medulloblastoma tissue samples with leptomeningeal dissemination, researchers found decreased microRNA 192 (miR-192); when they overexpressed miR-192 in vitro, they found that $\mathrm{CD} 47$ was repressed, affecting integrin alpha $\mathrm{V}$ activation and cell proliferation ${ }^{[38]}$. Finally, a variety of pediatric solid tumor histologies, including Ewing sarcoma, medulloblastoma, atypical teratoid/rhabdoid tumor, primitive neuroectodermal tumor, pediatric high-grade glioma, and diffuse intrinsic pontine glioma were found to have diffuse CD47 expression; the brain tumors all showed response to CD47 blockade in xenograft models ${ }^{[39,40]}$.

To help guide studies of CD47 blockade in pediatric oncology, we sought to identify which histologies express high levels of CD47. We analyzed publicly available RNA-seq expression data from the Treehouse Childhood Cancer Initiative at the UC Santa Cruz Genomics Institute, which includes a total of 12,211 samples of both adult and pediatric cases [Figure 1]. We downloaded RNA-seq expression data and their associated patient-privacy protected clinical data (https://treehousegenomics.soe.ucsc.edu/publicdata/\#tumor_v10_polyA) on December 4, 2019. All expression data were uniformly processed and normalized by Treehouse Childhood Cancer Initiative (https://github.com/BD2KGenomics/toil-rnaseq). Gene expression was quantified as transcript per million (TPM). R packages data.table 1.12.2, ggplot2 3.2.1 and R 3.6.0 were used to plot the CD47 expression panel ${ }^{[41-43]}$.

We also created a "pediatric cancer" data subset, which included all ages for histologies that are classically diagnosed in pediatric, adolescent or young adult patients but was limited to those patients under 19 years for histologies that span a broad age range [Figure 2]. Data are shown normalized to the expression of all genes across the database.

On average, essentially all cancers express CD47 mRNA, mostly ranging 2-8 $\log _{2}$ (4-256 TPM for all genes). Among pediatric cancers, we find the highest expression of CD47 in M7 AML and ALL, nearly as 

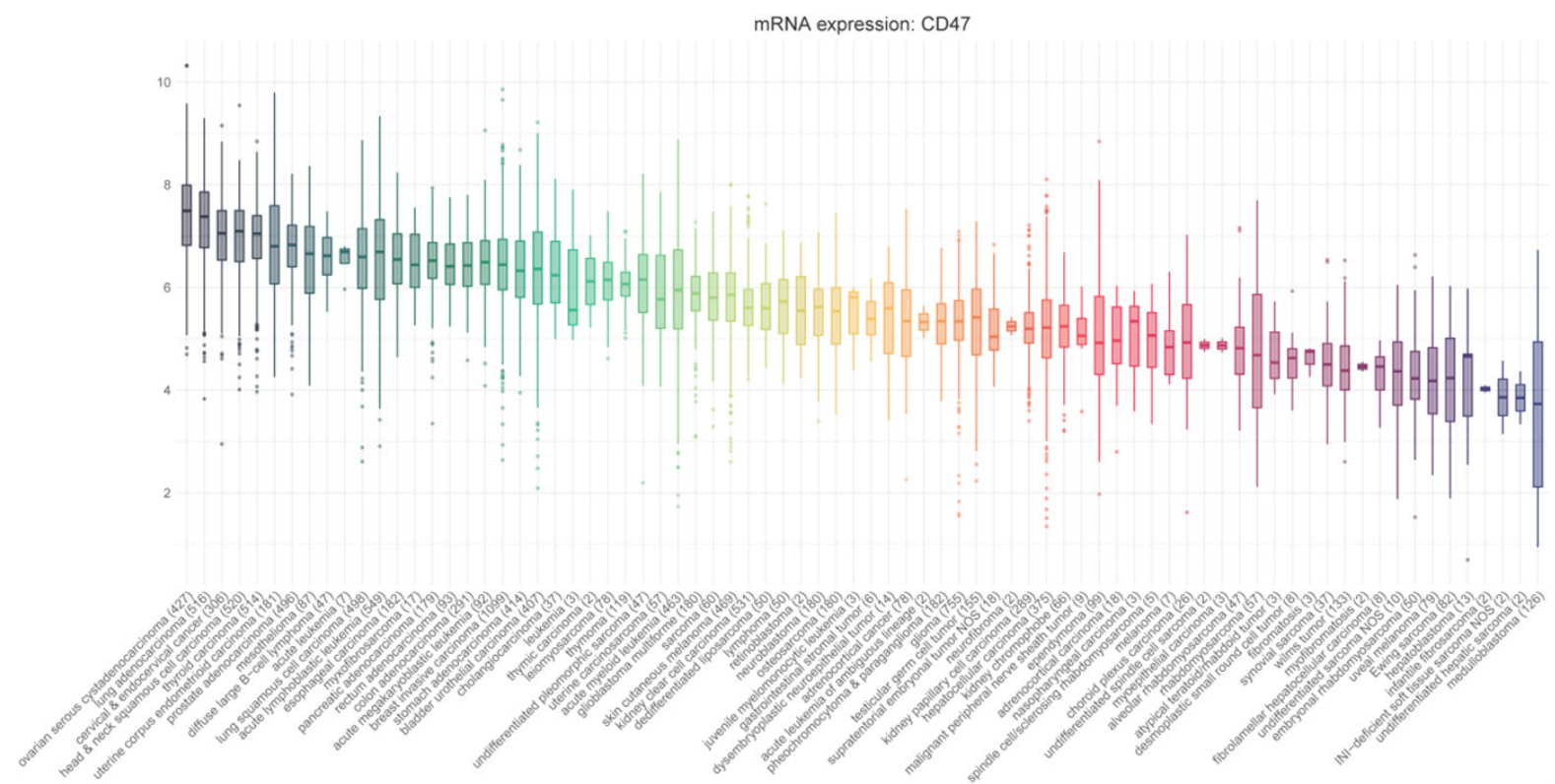

Figure 1. CD47 expression across all cases. We included all Treehouse data with at least 2 samples and ordered them by their average normalized expression. Y-axis represents log2 normalized or $\log 2(T P M+1)$ expression of CD47. X-axis shows the diseases with the number of samples in the parenthesis

\section{mRNA expression: CD47}
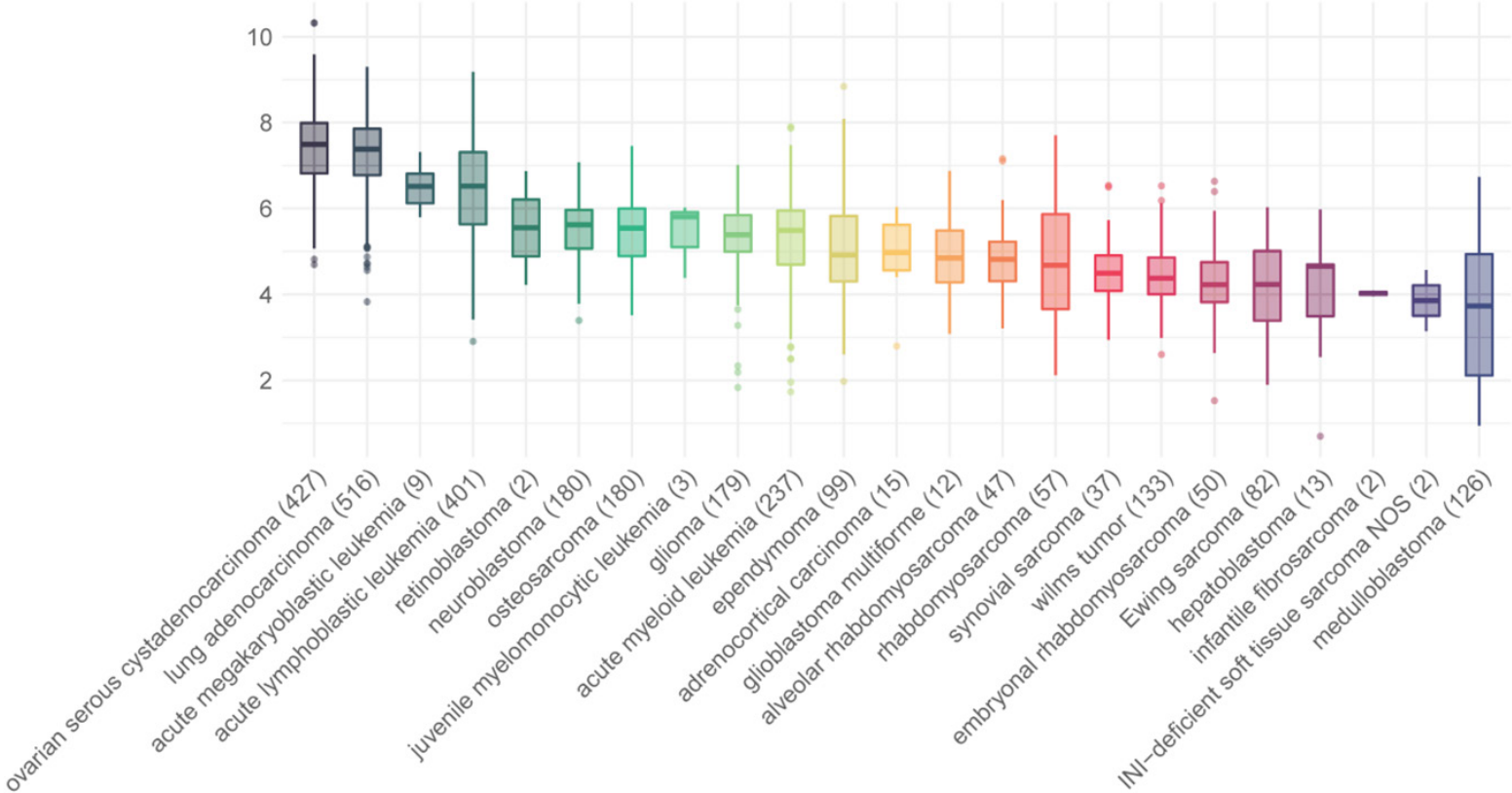

Figure 2. CD47 across pediatric histologies. For comparison, we included the top two adult expressing tumor types (ovarian serous cystadenocarcinoma and lung adenocarcinoma). For those histologies that are shared between pediatric and adults (e.g., acute lymphoblastic leukemia, acute megakaryoblastic leukemia, acute myeloid leukemia, adrenocortical carcinoma, glioblastoma multiforme, and glioma), we only included cases under age 19; for those histologies that are classically a pediatric diagnosis (all others), we included all ages to capture data in young adults with pediatric diagnoses as well. We only included histologies with at least 2 patient samples. We ordered the data by their average normalized expression. Y-axis represents $\log 2$ normalized or $\log 2(T P M+1)$ expression of CD47.. $X$-axis shows the diseases with the number of observations in parentheses 


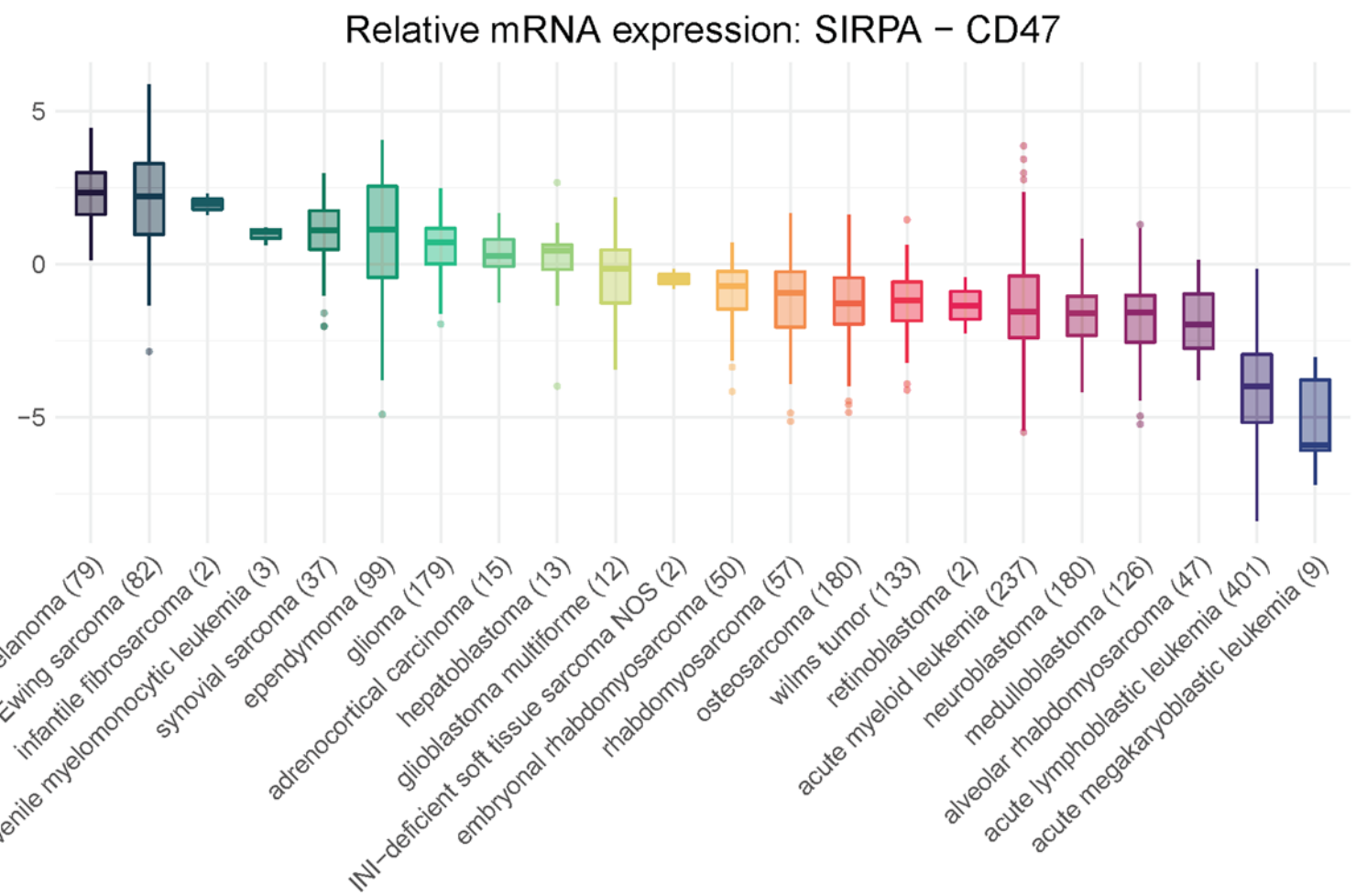

Figure 3. SIRP $\alpha$ to CD47 relative mRNA expression. Included are the expression panels for pediatric cases as described in Figure 2. $\mathrm{Y}$-axis in these two panels is the relative expression of SIRP $\alpha$ as compared to CD47 expression [i.e., $\log _{2}(\mathrm{TPM}+1)$ expression of SIRP $\alpha$ $\log _{2}(T P M+1)$ expression of CD47]. Positive value means expression of SIRP $\alpha$ is $\log _{2}$ fold change higher than CD47 expression and vice versa. Boxplots are ordered by their average relative expression. SIRP $\alpha$ : signal regulatory protein $\alpha$

high as the highest adult cancers. Expression is slightly lower in a variety of pediatric solid tumors such as retinoblastoma, neuroblastoma, osteosarcoma and others, with medulloblastoma showing the lowest average expression. The rank order is somewhat reminiscent of tumor mutational burden ${ }^{[4]}$, suggesting there may be a correlation between tumor immunogenicity and CD47 expression. That said, the range of expression amongst samples within each histology is quite wide. Thus, as the blockade of CD47 depends on its expression, it will likely vary considerably from case to case.

Given the suggested importance of surface expression of corresponding ligands on tumor immune infiltrate, we also examined the same pediatric cancers for SIRP $\alpha$ [Figure 3]. Many histologies demonstrate surface expression of SIRP $\alpha$ on par with that of CD47, suggesting that the interaction between the two is likely relevant. The lower expression of SIRP $\alpha$ in leukemias is likely because many of the samples were taken from peripheral blood and thus do not reflect the bone marrow microenvironment. We also studied additional ligands known to interact with CD47 such as TSP-1 and signaling lymphocytic activation molecule F7 (SLAMF7) (data not shown). Our data demonstrate a similar relationship between TSP-1 and $\mathrm{CD} 47$, with a majority of pediatric solid tumor microenvironments showing equivalent expression of both ligands. As mentioned earlier, TSP-1 is another ligand for CD47 on many cell types, including innate immune cells, and studies have shown that CD47 binding to TSP- 1 affects macrophage recruitment, IL- $1 \beta$ production, and the expression of cancer stem cell transcription factors ${ }^{[45]}$. Increased SLAMF7 expression on either tumor or immune cells may govern a macrophage's ability to engulf hematopoietic tumor cells in response to $\mathrm{CD} 47$ blockade $^{[46]}$, although this result has been called into question ${ }^{[47]}$. Our data seem to echo the questionable role of this ligand, and SLAMF7 shows uniformly low expression compared to CD47. 


\section{THERAPEUTIC ADVANCES/COMBINATION THERAPIES}

The observed success of immunotherapy in today's therapeutic landscape indicates that, while we have established an anticancer modality that can be effective, significant improvements are needed to broaden survival benefit over time. Although $\mathrm{CD} 47$ has a major role in regulating phagocytosis, it is actually $\mathrm{F} c \gamma \mathrm{R}$ engagement that is requisite for phagocytosis; mice that are CD47-deficient have a largely normal phenotype, other than mild anemia or thrombocytopenia, without overt autoimmunity ${ }^{[17]}$. CD 47 blockade may also trigger $\mathrm{T}$ cells via stimulator of interferon genes (STING)-based cytosolic sensing of tumor cell DNA $^{[20]}$. Tenascin C (an extracellular matrix protein) and hypoxia-inducible factor are also thought to mediate CD47-associated changes in the tumor microenvironment ${ }^{[24,4]}$.

On the other side of the interaction, SIRP $\alpha$ blockade may achieve similar goals via antibody-mediated tumor cell destruction, increased licensing of the cytokine IL-12, and negative regulation of proinflammatory pathways ${ }^{[8,32]}$. IL-12 mediates T helper type 1 cell (Th1) polarization of activated CD4 T cells and subsequent amplification of the CD8 cytotoxic lymphocyte respons $\mathrm{e}^{[8]}$. When mice are administered an antigen-pulsed DC-based vaccine with lentiviral expression of miRNA that silences SIRP $\alpha$, there is greater DC activation, T cell proliferation, interferon gamma production, and cytolytic activity ${ }^{[8]}$. Anti-SIRP $\alpha$ antibodies appear to target neutrophils and macrophages that are contributing to tumor growth in vitro and in $v i v o^{[49]}$. Some macrophages express both SIRP $\alpha$ and CD47, and it was recently shown that inhibiting both receptors on the same macrophage creates a hyper-phagocytic state ${ }^{[50]}$. The effect of blocking SIRP $\alpha$ has been shown to be attenuated by the depletion of macrophages, CD8+ T cells, and NK cells ${ }^{[51]}$. Moreover, CD47 overexpression may blunt the therapeutic action of monoclonal antibodies, and therefore, CD47 blockade would enhance antibody efficacy ${ }^{[52]}$. Additional strategies to block this axis involve engineered SIRP $\alpha$ monomers or exosomes with SIRP $\alpha$ that have a high affinity for CD47 and that would similarly lower the macrophage threshold for phagocytosis and, as a result, $\mathrm{T}$ cell activation ${ }^{[15,53]}$. A comprehensive review of the various types of anti-CD47 and anti-SIRP $\alpha$ blocking agents has recently been published ${ }^{[46]}$.

On the basis of the findings reported so far, it is logical to hypothesize that solely blocking the CD47SIRP $\alpha$ axis in humans will be insufficient to elicit an antitumor phagocytic effect. Thus, combination therapies and the identification of new checkpoints to inhibit, especially from both the adaptive and innate immune standpoints, may help address this deficit ${ }^{[54]}$. Investigators have already examined various in vitro and in vivo combinations with anti-CD47, including PD-L1 or CTLA-4 blockade, monoclonal antibodies, chemotherapy, and radiation. There is evidence that TAMs express PD-1, have increased PD-1 expression over time and with higher disease stage, and have a decreased ability to phagocytose $\mathrm{PD}-\mathrm{L} 1$-expressing tumor cells ${ }^{[55]}$, lending a rational approach to combination blockade of PD-L1 and $\mathrm{CD} 47^{[52]}$. Similar evidence has been presented for CTLA- $4^{[56]}$. Researchers designed epithelial cell adhesion molecule-targeted cationic liposomes containing siRNA for both PD-L1 and CD47 and found significant in vivo decrement in solid tumor burden and metastases ${ }^{[57]}$. By combining CD47-SIRP $\alpha$ disruption with IgA antibodies against HER2, one group was able to enhance tumor cell opsonization and decrease tumor burden via neutrophil trogocytosis, a method of acquiring target cell plasma membrane fragments ${ }^{[10]}$. Similar results were produced with the addition of monoclonal antibodies such as rituximab (anti-CD20), alemtuzumab (anti-CD52), lorvotuzumab (anti-CD56), trastuzumab (anti-HER2), cetuximab (antiEGFR), and anti-CD271 (nerve growth factor receptor) ${ }^{[53,58,59]}$. Synergy has been demonstrated between $\mathrm{CD} 47$ binding and anti-angiogenic, anti-T cell receptor mimetic for PRAME (preferentially expressed antigen in melanoma), tyrosine kinase inhibitor (sorafenib), or anti-Bcl2 (venetoclax) therapy ${ }^{[60-63]}$. When considering the combination of chemotherapy with CD47 blockade, chemotherapy may lead to increased tumor infiltration by antigen-presenting cells (APCs), increased antigen release, and increased calreticulin expression $^{[64,65]}$, but may also suppress the immune system and thus blunt the effect of CD47 blockade ${ }^{[20]}$. It may be that the sequence of therapies will be important. For example, the in vivo combination of anti-CD47 treatment with cyclophosphamide or paclitaxel for mouse A20 lymphoma tumors resulted in maximum 
synergy with chemotherapy given 1 day prior to $\mathrm{CD} 47$ blockade rather than 3 days after ${ }^{[20]}$. Chemotherapy may induce the infiltration of TAMs into the tumor, and anti-CD47 therapy could subsequently convert them into effector cells ${ }^{[66]}$. Anthracyclines can mediate susceptibility to a blocking antibody against CD47, increase translocation of calreticulin to the cell surface, and intensify macrophage activity ${ }^{[3,67]}$; in vivo studies have shown successful combination therapy against osteosarcoma ${ }^{[68]}$. In this setting, CD47 blockade may have cardioprotective properties mediated by an increase in autophagy ${ }^{[69]}$. Finally, a particularly innovative approach using an oxaliplatin prodrug and a pegylated photosensitizer activated by tumor microenvironment-associated matrix metalloproteinase-2 (MMP2) showed synergy with injection of CD47 antibodies into the tumor ${ }^{[70]}$.

Local control may be aided by anti-CD47 treatment. In mice treated with debulking surgery for glioblastoma multiforme xenografts, antibodies injected into the resection cavity led to prolonged survival, increased macrophage infiltration, and increased pro-inflammatory cytokines ${ }^{[71]}$. Near-infrared photoimmunotherapy has been developed with CD47 antibodies with good local tumor control in vivo ${ }^{[72]}$. CD47 blockade may also enhance tumor radiosensitivity via improved CD8 $\mathrm{T}$ cell immunosurveillance in syngeneic mouse models ${ }^{[18]}$, STING-based tumor visibility ${ }^{[73]}$, and selective upregulation of protective pathways against oxidative stress and upregulation of DNA repair in normal tissues ${ }^{[7]}$. Signals for autophagy are turned on in endothelial cells and T cells, resulting in increased blood flow within tumors and enhancing the penetration of cytotoxic lymphocytes both locally and possibly at distant tumor sites ${ }^{[18]}$, the off-stage, on-target result known as the abscopal effect. Treatment with anti-CD47 antibody plus antiHER2 antibody or temozolamide in mice results in radiosensitization and improves survival over that with either therapy alone ${ }^{[73,75]}$. In another study, microRNA 222 (miR-222) was found to negatively regulate CD47 expression, and overexpression of miR-222 enhanced cancer cell radiosensitivity via the CD47pERK pathway ${ }^{[76]}$. While signals for autophagy may be radioprotective for normal tissue, other studies have shown that blocking tumor autophagy with chloroquine and anti-CD47 is an effective antitumor strategy in vivo ${ }^{[77]}$.

In clinical trials, investigators have started adding anti-CD47 therapy to well-established lines of therapy in different adult cancers, including a successful study in rituximab-resistant non-Hodgkin lymphoma with a humanized anti-CD47 antibody, Hu5F9-G4, and rituximab ${ }^{[78]}$. Preclinical work on this synergy appeared to support two mechanisms for its action, namely Fc receptor (FcR)-independent anti-CD47 blockade and FcR-dependent pro-phagocytosis signal via rituximab ${ }^{[27]}$. In addition, rituximab induces complement and NK-mediated ADCC ${ }^{[78]}$. In that study, 22 refractory non-Hodgkin's lymphoma patients were treated in a phase $1 \mathrm{~b}$ study of Hu5F9-G4 plus rituximab. It was very well tolerated with two grade 3-4 hematological adverse events and an impressive objective response rate of 50\%, with $36 \%$ of the patients having a complete response. The median duration of response was not reached at more than 6 to 8 months of follow-up ${ }^{[78]}$. Prior concerns of the ubiquity of CD47 on normal hematopoietic cells that may act as an "antigen sink" with subsequent off-target toxicity may be mitigated by these results.

On-going trials are utilizing CD47 blockade plus PD-1/PD-L1 inhibitors (NCT02663518, NCT02890368, NCT03013218 and NCT03530683, NCT03558139), ramucirumab and paclitaxel (NCT03013218), 5-FU and cisplatin (NCT03013218), azacitidine (NCT03248479), cetuximab (NCT02953782), carfilzomib (NCT03530683), radiation (NCT02890368), pegylated interferon- $\alpha 2$ a (NCT02890368), and talimogene laherparepvec (T-Vec) (NCT02890368). Preliminary results from NCT03248479 demonstrate good tolerance of combination therapy with azacitidine ${ }^{[79]}$. However, none of these trials allow patients under 18 years of age.

Next-generation CD47 blockade has resulted in bispecific antibody platforms that can also target CD19 or CD20 in a mouse lymphoma model ${ }^{[80-82]}, \mathrm{CD} 33$ or $\mathrm{CD} 123$ in $\mathrm{AML}^{[83-85]}, \mathrm{CD} 40$ in colon carcinoma ${ }^{[86]}$, 


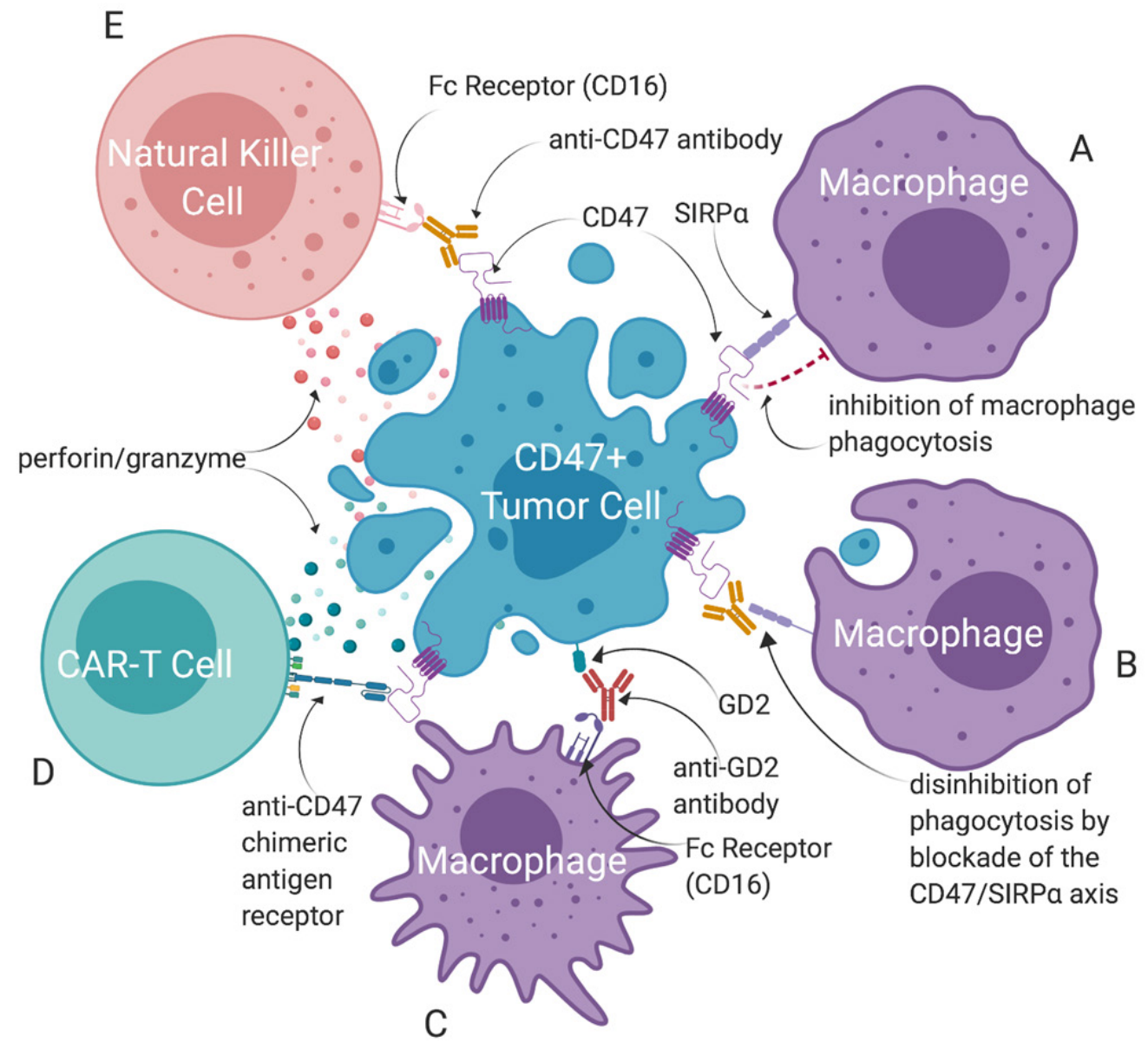

Figure 4. Targets to prioritize in combination with CD47 blockade. Targeting CD47 can alter immune effector response to the tumor microenvironment in a variety of ways. Where typically the interaction between SIRP $\alpha$ on the macrophage and CD47 on the tumor inhibits tumor cell phagocytosis by the macrophage (A), anti-CD47 antibodies can disrupt this interaction, permitting phagocytosis (B). This blockade of the CD47/SIRP $\alpha$ axis can be paired with other targeted antibody therapies, exemplified here with anti-GD2 antibody dinutuximab, to target tumor cells through the macrophage Fc receptor (C). T cells can be genetically engineered to express anti-CD47 CAR directly targeting CD47+ tumor cells for lysis (D). Similarly, natural killer cells can engage CD47+ tumor cells through antibodydependent cellular cytotoxicity via anti-CD47 antibody interaction with the Fc receptor (E). CAR: chimeric antigen receptors; SIRPa: signal regulatory protein $\alpha$

tumor-associated antigens such as mesothelin ${ }^{[87]}$ and VEGFR1 ${ }^{[60]}$ in non-small cell lung cancer, and even dual blockade of CD47 and SIRP $\alpha^{[88,89]}$ or SIRP $\alpha$ and PD-L1 ${ }^{[90]}$; however, trials in humans have yet to be conducted. CD96, like CD123, has been suggested as a leukemic stem cell-specific molecule that also engages $\mathrm{Fc}$ receptors on phagocytes ${ }^{[26]}$, and might be an effective target in combination with anti-CD47. CD47 antibody has been fused with GM-CSF, enabling M1 macrophage polarization and antitumor effect $^{[91]}$. Nanobodies (single-domain antibody fragments) targeting CD47 have been constructed with decreased affinity for human red blood cells and also conjugated to rituximab as a novel bispecific antibody with in vivo antitumor effect ${ }^{[92]}$. Chimeric antigen receptor-T (CAR-T) cells have been engineered to emit these nanobodies and may have the ability to simultaneously produce nanobodies for different targets, including CD47, PD-L1, or CTLA- ${ }^{[93]}$. One group has capitalized on the cytotoxicity of certain CD47 antibodies, creating an antibody that shows both a direct antitumor effect and increased macrophage phagocytosis and decreased red blood cell destruction ${ }^{[94]}$. Oncolytic adenoviruses expressing a SIRP $\alpha$-Fc fusion protein have been shown to have macrophage-dependent cytotoxicity against ovarian xenografts, in addition to the inherently lytic properties of the virus, and they deserve broader study ${ }^{[95]}$. More recently, two groups independently used syngeneic inactivated tumor cells deficient in CD47 as a vaccine in vivo to 
stimulate immune recognition of existing mouse melanoma or lymphoma ${ }^{[9,96]}$. The first study noted that the vaccinated mice had increased tumor-infiltrating NK cells; in the tumors that failed to respond to the vaccines, there were elevated regulatory T cells, higher PD-L1 expression, and increased M2 macrophages ${ }^{[9]}$, all together portraying an exhaustion phenotype. When the second group employed combination blockade of tumor vaccine and PD-L1, they found synergistic antitumor responses ${ }^{[96]}$.

\section{CONCLUSION}

Advances in immunotherapy have begun to involve the long-ignored innate immune system, but pediatric cancers have yet to benefit. Engaging phagocytes allows both direct tumor kill and indirect engagement of cytotoxic T cells via APCs and STING. This dual threat is further strengthened by combination with additional immunotherapy aimed at T cells (checkpoint inhibition) or FcR and ADCC (monoclonal antibodies) and may even get to the root of treatment resistance by eliminating cancer stem cells. Future trials may prioritize the combination of anti-CD47 therapy with targeted antibodies against known receptors such as GD2 [Figure 4], CD47-specific CAR-T cells, NK cells, or tumor vaccines. According to our analysis, while CD47 blockade may be effective across many, if not all, cancer histologies, the patients most likely to benefit will be those with the highest surface expression of this marker. Given the range of variability in expression, patients should be selected on a case-by-case basis.

As we move the focus to hitherto unexplored territories, including rare and pediatric histologies and nextgeneration CD47 blockade in combination with more effective immunotherapies and chemotherapies, we will hopefully overwhelm cancer's voracious appetite by endowing our immune system with its own set of teeth.

\section{DECLARATIONS}

\section{Acknowledgments}

Figure 4 was created with BioRender.

\section{Authors' contributions}

Conceived the study: Cripe TP, Gupta A

Wrote the manuscript (first draft): Gupta A

Wrote, reviewed, discussed, edited, and revised the manuscript: Cripe TP, Gupta A

Made substantial contributions to conception and design of the study figures and performed data analysis and interpretation: Taslim C, Tullius BP

\section{Availability of data and materials}

Not applicable.

\section{Financial support and sponsorship}

None.

\section{Conflicts of interest}

All authors declared that there are no conflicts of interest.

\section{Ethical approval and consent to participate}

Not applicable.

\section{Consent for publication}

Not applicable. 


\section{Copyright}

(c) The Author(s) 2020.

\section{REFERENCES}

1. Barkal AA, Weiskopf K, Kao KS, Gordon SR, Rosental B, et al. Engagement of MHC class I by the inhibitory receptor LILRB1 suppresses macrophages and is a target of cancer immunotherapy. Nat Immunol 2018;19:76-84.

2. Liu P, Zhao L, Loos F, Marty C, Xie W, et al. Immunosuppression by mutated calreticulin released from malignant cells. Mol Cell 2020;77:748-60.e9.

3. Gardai SJ, McPhillips KA, Frasch SC, Janssen WJ, Starefeldt A, et al. Cell-surface calreticulin initiates clearance of viable or apoptotic cells through trans-activation of LRP on the phagocyte. Cell 2005;123:321-34.

4. Willingham SB, Volkmer JP, Gentles AJ, Sahoo D, Dalerba P, et al. The CD47-signal regulatory protein alpha (SIRPa) interaction is a therapeutic target for human solid tumors. Proc Natl Acad Sci 2012;109:6662-7.

5. Sakakura K, Takahashi H, Kaira K, Toyoda M, Murata T, et al. Relationship between tumor-associated macrophage subsets and CD47 expression in squamous cell carcinoma of the head and neck in the tumor microenvironment. Lab Investig 2016;96:994-1003.

6. Zhang M, Hutter G, Kahn SA, Azad TD, Gholamin S, et al. Anti-CD47 treatment stimulates phagocytosis of glioblastoma by M1 and M2 polarized macrophages and promotes M1 polarized macrophages in vivo. PLoS One 2016;11:e0153550.

7. Zhang Y, Sime W, Juhas M, Sjölander A. Crosstalk between colon cancer cells and macrophages via inflammatory mediators and CD47 promotes tumour cell migration. Eur J Cancer 2013;49:3320-34.

8. Liu Q, Wen W, Tang L, Qin CJ, Lin Y, et al. Inhibition of SIRP $\alpha$ in dendritic cells potentiates potent antitumor immunity. Oncoimmunology 2016;5:e1183850.

9. Jayaraman Rukmini S, Bi H, Sen P, Everhart B, Jin S, et al. Inducing tumor suppressive microenvironments through genome edited $\mathrm{CD} 7^{-1}$ syngeneic cell vaccination. Sci Rep 2019;9:20057.

10. Treffers LW, Ten Broeke T, Rösner T, Jansen JHM, van Houdt M, et al. IgA-mediated killing of tumor cells by neutrophils is enhanced by CD47-SIRP $\alpha$ checkpoint inhibition. Cancer Immunol Res 2020;8:120-30.

11. Kim MJ, Lee JC, Lee JJ, Kim S, Lee SG, et al. Association of CD47 with natural killer cell-mediated cytotoxicity of head-and-neck squamous cell carcinoma lines. Tumour Biol 2008;29:28-34.

12. Nath PR, Pal-Nath D, Mandal A, Cam MC, Schwartz AL, et al. Natural killer cell recruitment and activation are regulated by CD47 expression in the tumor microenvironment. Cancer Immunol Res 2019;7:1547-61.

13. Boukhari A, Alhosin M, Bronner C, Sagini K, Truchot C, et al. CD47 activation-induced UHRF1 over-expression is associated with silencing of tumor suppressor gene p16INK4A in glioblastoma cells. Anticancer Res 2015;35:149-58.

14. Kaur S, Schwartz AL, Jordan DG, Soto-Pantoja DR, Kuo B, et al. Identification of schlafen-11 as a target of CD47 signaling that regulates sensitivity to ionizing radiation and topoisomerase inhibitors. Front Oncol 2019;9:994.

15. Koh E, Lee EJ, Nam GH, Hong Y, Cho E, et al. Exosome-SIRPa, a CD47 blockade increases cancer cell phagocytosis. Biomaterials 2017;121:121-9.

16. Jaiswal S, Jamieson CHM, Pang WW, Park CY, Chao MP, et al. CD47 is upregulated on circulating hematopoietic stem cells and leukemia cells to avoid phagocytosis. Cell 2009;138:271-85.

17. Matlung HL, Szilagyi K, Barclay NA, van den Berg TK. The CD47-SIRP $\alpha$ signaling axis as an innate immune checkpoint in cancer. Immunol Rev 2017;276:145-64.

18. Soto-Pantoja DR, Terabe M, Ghosh A, Ridnour LA, DeGraff WG, et al. Cd47 in the tumor microenvironment limits cooperation between antitumor t-cell immunity and radiotherapy. Cancer Res 2014;74:6771-83.

19. Kikuchi Y, Uno S, Kinoshita Y, Yoshimura Y, Iida SI, et al. Apoptosis inducing bivalent single-chain antibody fragments against CD47 showed antitumor potency for multiple myeloma. Leuk Res 2005;29:445-50.

20. Liu X, Pu Y, Cron K, Deng L, Kline J, et al. CD47 blockade triggers T cell-mediated destruction of immunogenic tumors. Nat Med 2015;21:1209-15.

21. Campbell IG, Freemont PS, Foulkes W, Trowsdale J. An ovarian tumor marker with homology to vaccinia virus contains an IgV-like region and multiple transmembrane domains. Cancer Res 1992;52:5416-20.

22. Pai S, Bamodu OA, Lin YK, Lin CS, Chu PY, et al. CD47-SIRP $\alpha$ signaling induces epithelial-mesenchymal transition and cancer stemness and links to a poor prognosis in patients with oral squamous cell carcinoma. Cells 2019;8:1658.

23. Li F, Lv B, Liu Y, Hua T, Han J, et al. Blocking the CD47-SIRP $\alpha$ axis by delivery of anti-CD47 antibody induces antitumor effects in glioma and glioma stem cells. Oncoimmunology 2018;7:e1391973.

24. Zhang H, Lu H, Xiang L, Bullen JW, Zhang C, et al. HIF-1 regulates CD47 expression in breast cancer cells to promote evasion of phagocytosis and maintenance of cancer stem cells. Proc Natl Acad Sci U S A 2015;112:E6215-23.

25. Theocharides APA, Jin L, Cheng PY, Prasolava TK, Malko A V, et al. Disruption of SIRP $\alpha$ signaling in macrophages eliminates human acute myeloid leukemia stem cells in xenografts. J Exp Med 2012;209:1883-99.

26. Majeti R, Chao MP, Alizadeh AA, Pang WW, Jaiswal S, et al. CD47 is an adverse prognostic factor and therapeutic antibody target on human acute myeloid leukemia stem cells. Cell 2009;138:286-99.

27. Chao MP, Alizadeh AA, Tang C, Myklebust JH, Varghese B, et al. Anti-CD47 antibody synergizes with rituximab to promote phagocytosis and eradicate non-hodgkin lymphoma. Cell 2010;142:699-713.

28. Brightwell RM, Grzankowski KS, Lele S, Eng K, Arshad M, et al. The CD47 “don’t eat me signal” is highly expressed in human ovarian 
cancer. Gynecol Oncol 2016;143:393-7.

29. Chao MP, Alizadeh AA, Tang C, Jan M, Weissman-Tsukamoto R, et al. Therapeutic antibody targeting of CD47 eliminates human acute lymphoblastic leukemia. Cancer Res 2011;71:1374-84.

30. Tsao LC, Crosby EJ, Trotter TN, Agarwal P, Hwang BJ, et al. CD47 blockade augmentation of trastuzumab antitumor efficacy dependent on antibody-dependent cellular phagocytosis. JCI Insight 2019;4.

31. Johnson LDS, Banerjee S, Kruglov O, Viller NN, Horwitz SM, et al. Targeting CD47 in Sézary syndrome with SIRPaFc. Blood Adv 2019;3:1145-53.

32. Zhao XW, Van Beek EM, Schornagel K, Van Der Maaden H, Van Houdt M, et al. CD47-signal regulatory protein- $\alpha$ (SIRP $\alpha$ ) interactions form a barrier for antibody-mediated tumor cell destruction. Proc Natl Acad Sci U S A 2011;108:18342-7.

33. Irandoust M, Alvarez Zarate J, Hubeek I, van Beek EM, Schornagel K, et al. Engagement of SIRP $\alpha$ inhibits growth and induces programmed cell death in acute myeloid leukemia cells. PLoS One 2013;8:e52143.

34. Xu JF, Pan XH, Zhang SJ, Zhao C, Qiu BS, et al. CD47 blockade inhibits tumor progression human osteosarcoma in xenograft models. Oncotarget 2015;6:23662-70.

35. Piperdi S, Roth M, Morriss N, Zinone C, Zhang W, et al. Abstract 2471: evaluation of CD47 expression and effects of CD47-SIRPa fusion protein in patients with osteosarcoma. Cancer Res 2016;76:2471. Available from: http://cancerres.aacrjournals.org/content/76/14_ Supplement/2471.abstract [Last accessed on 8 Apr 2020]

36. Herrmann D, Seitz G, Fuchs J, Armeanu-Ebinger S. Susceptibility of rhabdomyosarcoma cells to macrophage-mediated cytotoxicity. Oncoimmunology 2012;1:279-86.

37. Jeanne A, Martiny L, Dedieu S. Thrombospondin-targeting TAX2 peptide impairs tumor growth in preclinical mouse models of childhood neuroblastoma. Pediatr Res 2017;81:480-8.

38. Yang SY, Choi SA, Lee JY, Park AK, Wang KC, et al. miR-192 suppresses leptomeningeal dissemination of medulloblastoma by modulating cell proliferation and anchoring through the regulation of DHFR, integrins, and CD47. Oncotarget 2015;6:43712-30.

39. Gholamin S, Mitra SS, Feroze AH, Liu J, Kahn SA, et al. Disrupting the CD47-SIRPa anti-phagocytic axis by a humanized anti-CD47 antibody is an efficacious treatment for malignant pediatric brain tumors. Sci Transl Med 2017;9.

40. Mitra SS, Gholamin S, Volkmer JP, Feroze A, Liu J, et al. Abstract PR12: overcoming immune evasion in pediatric hematologic and solid tumor malignancies: A preclinical study using a humanized anti-CD47 antibody. Cancer Res 2014;74:PR12. Available from: http:// cancerres.aacrjournals.org/content/74/20_Supplement/PR12.abstract [Last accessed on 8 Apr 2020]

41. Dowle M, Srinivasan A. data.table: Extension of data.frame. 2019. Available from:https://CRAN.R-project.org/package=data.table [Last accessed on 13 Apr 2020]

42. Wickham H. ggplot2: elegant graphics for data analysis. New York: Springer-Verlag; 2016.

43. Core R Team. R: A language and environment for statistical computing. Vienna, Austria; 2019.

44. Gröbner SN, Worst BC, Weischenfeldt J, Buchhalter I, Kleinheinz K, et al. The landscape of genomic alterations across childhood cancers. Nature 2018;555:321-7.

45. Stein E V, Miller TW, Ivins-O'Keefe K, Kaur S, Roberts DD. Secreted thrombospondin-1 regulates macrophage interleukin-1 $\beta$ production and activation through CD47. Sci Rep 2016;6:19684.

46. Veillette A, Chen J. SIRP $\alpha-C D 47$ immune checkpoint blockade in anticancer therapy. Trends Immunol 2018;39:173-84.

47. He Y, Bouwstra R, Wiersma VR, de Jong M, Jan Lourens H, et al. Cancer cell-expressed SLAMF7 is not required for CD47-mediated phagocytosis. Nat Commun 2019;10:533.

48. Ma D, Liu S, Lal B, Wei S, Wang S, et al. Extracellular matrix protein tenascin C increases phagocytosis mediated by CD47 loss of function in glioblastoma. Cancer Res 2019;79:2697-708.

49. Ring NG, Herndler-Brandstetter D, Weiskopf K, Shan L, Volkmer JP, et al. Anti-SIRP $\alpha$ antibody immunotherapy enhances neutrophil and macrophage antitumor activity. Proc Natl Acad Sci U S A 2017;114:E10578-85.

50. Hayes BH, Tsai RK, Dooling LJ, Kadu S, Lee JY, et al. Macrophages eat more after disruption of cis interactions between CD47 and the checkpoint receptor SIRP $\alpha$. J Cell Sci 2020;133.

51. Yanagita T, Murata Y, Tanaka D, Motegi SI, Arai E, et al. Anti-SIRP $\alpha$ antibodies as a potential new tool for cancer immunotherapy. JCI Insight 2017;2:e89140.

52. Sockolosky JT, Dougan M, Ingram JR, Ho CCM, Kauke MJ, et al. Durable antitumor responses to CD47 blockade require adaptive immune stimulation. Proc Natl Acad Sci U S A 2016;113:E2646-54.

53. Weiskopf K, Ring AM, Ho CCM, Volkmer JP, Levin AM, et al. Engineered SIRP $\alpha$ variants as immunotherapeutic adjuvants to anticancer antibodies. Science 2013;341:88-91.

54. Casey SC, Tong L, Li Y, Do R, Walz S, et al. MYC regulates the antitumor immune response through CD47 and PD-L1. Science 2016;352:227-31.

55. Gordon SR, Maute RL, Dulken BW, Hutter G, George BM, et al. PD-1 expression by tumour-associated macrophages inhibits phagocytosis and tumour immunity. Nature 2017;545:495-9.

56. Schwartz AL, Nath P, Lessey-Morillon E, Ridnour L, Allgaeuer M, et al. CTLA4 and CD47 combinational therapy to extend survival in melanoma. J Clin Oncol 2017;35:e21025.

57. Lian S, Xie R, Ye Y, Xie X, Li S, et al. Simultaneous blocking of CD47 and PD-L1 increases innate and adaptive cancer immune responses and cytokine release. EBioMedicine 2019;42:281-95.

58. Ngo M, Han A, Lakatos A, Sahoo D, Hachey SJ, et al. Antibody therapy targeting CD47 and CD271 effectively suppresses melanoma metastasis in patient-derived xenografts. Cell Rep 2016;16:1701-16. 
59. Weiskopf K, Jahchan NS, Schnorr PJ, Cristea S, Ring AM, et al. CD47-blocking immunotherapies stimulate macrophage-mediated destruction of small-cell lung cancer. J Clin Invest 2016;126:2610-20.

60. Zhang X, Wang Y, Fan J, Chen W, Luan J, et al. Blocking CD47 efficiently potentiated therapeutic effects of anti-angiogenic therapy in non-small cell lung cancer. J Immunother Cancer 2019;7:346.

61. Mathias MD, Sockolosky JT, Chang AYY, Liu C, Garcia KC, et al. CD47 blockade enhances therapeutic activity of TCR mimic antibodies to ultra-low density cancer epitopes through cytokine feed forward mechanisms. Blood 2016;128:4048.

62. Valentin R, Peluso MO, Lehmberg TZ, Adam A, Zhang L, et al. The fully human anti-CD47 antibody SRF231 has dual-mechanism antitumor activity against chronic lymphocytic leukemia (CLL) Cells and increases the activity of both rituximab and venetoclax. Blood 2018; $132: 4393$.

63. Lo J, Lau EYT, Ng IOL, Lee TKW. Abstract 1911: NF-אB mediated CD47 upregulation promotes sorafenib resistance and its blockade synergizes the effect of sorafenib in hepatocellular carcinoma. Cancer Res 2014;74:1911. Available from: http://cancerres.aacrjournals. org/content/74/19_Supplement/1911.abstract [Last accessed on 8 Apr 2020]

64. Liu X, Kwon H, Li Z, Fu YX. Is CD47 an innate immune checkpoint for tumor evasion? J Hematol Oncol 2017;10:12.

65. Wilson C, Bouchlaka M, Puro R, Capoccia B, Hiebsch R, et al. Abstract B100: AO-176, a highly differentiated humanized anti-CD47 antibody, exhibits single-agent and combination antitumor efficacy with chemotherapy and targeted antibodies. Mol Cancer Ther 2019;18:B100. Available from: http://mct.aacrjournals.org/content/18/12_Supplement/B100.abstract [Last accessed on 8 Apr 2020]

66. Jaiswal S, Chao MP, Majeti R, Weissman IL. Macrophages as mediators of tumor immunosurveillance. Trends Immunol 2010;31:212-9.

67. Iribarren K, Buque A, Mondragon L, Xie W, Lévesque S, et al. Anticancer effects of anti-CD47 immunotherapy in vivo. Oncoimmunology 2019;8:1550619.

68. Mohanty S, Aghighi M, Yerneni K, Theruvath JL, Daldrup-Link HE. Improving the efficacy of osteosarcoma therapy: combining drugs that turn cancer cell 'don't eat me' signals off and 'eat me' signals on. Mol Oncol 2019;13:2049-61.

69. Feliz-Mosquea YR, Christensen AA, Wilson AS, Westwood B, Varagic J, et al. Combination of anthracyclines and anti-CD47 therapy inhibit invasive breast cancer growth while preventing cardiac toxicity by regulation of autophagy. Breast Cancer Res Treat 2018;172:69-82.

70. Zhou F, Feng B, Yu H, Wang D, Wang T, et al. Tumor microenvironment-activatable prodrug vesicles for nanoenabled cancer chemoimmunotherapy combining immunogenic cell death induction and CD47 blockade. Adv Mater 2019;31:e1805888.

71. Zhu H, Leiss L, Yang N, Rygh CB, Mitra SS, et al. Surgical debulking promotes recruitment of macrophages and triggers glioblastoma phagocytosis in combination with CD47 blocking immunotherapy. Oncotarget 2017;8:12145-57.

72. Kiss B, van den Berg NS, Ertsey R, McKenna K, Mach KE, et al. CD47-targeted near-infrared photoimmunotherapy for human bladder cancer. Clin Cancer Res 2019;25:3561-71.

73. Gholamin S, Youssef OA, Rafat M, Esparza R, Kahn S, et al. Irradiation or temozolomide chemotherapy enhances anti-CD47 treatment of glioblastoma. Innate Immun 2020;26:130-7.

74. Miller TW, Soto-Pantoja DR, Schwartz AL, Sipes JM, Degraff WG, et al. CD47 receptor globally regulates metabolic pathways that control resistance to ionizing radiation. J Biol Chem 2015;290:24858-74.

75. Candas D, Zhang L, Menaa C, Fan M, Zhang Y, et al. Abstract LB-226: Dual inhibition of CD47 and HER2 to radiosensitize breast cancer cells. Cancer Res 2017;77:LB-226. Available from: http://cancerres.aacrjournals.org/content/77/13_Supplement/LB-226.abstract [Last accessed on 8 Apr 2020]

76. Shi L, Wang X, Hu B, Wang D, Ren Z. miR-222 enhances radiosensitivity of cancer cells by inhibiting the expression of CD47. Int J Clin Exp Pathol 2019;12:4204-13.

77. Zhang X, Chen W, Fan J, Wang S, Xian Z, et al. Disrupting CD47-SIRP $\alpha$ axis alone or combined with autophagy depletion for the therapy of glioblastoma. Carcinogenesis 2018;39:689-99.

78. Advani R, Flinn I, Popplewell L, Forero A, Bartlett NL, et al. CD47 blockade by Hu5F9-G4 and rituximab in non-Hodgkin's lymphoma. N Engl J Med 2018;379:1711-21.

79. Sallman DA, Donnellan WB, Asch AS, Lee DJ, Al Malki M, et al. The first-in-class anti-CD47 antibody Hu5F9-G4 is active and well tolerated alone or with azacitidine in AML and MDS patients: initial phase 1b results. Available from: https:/ascopubs.org/doi/ abs/10.1200/JCO.2019.37.15_suppl.7009 [Last accessed on 13 Apr 2020]

80. Piccione EC, Juarez S, Tseng S, Liu J, Stafford M, et al. SIRP $\alpha$-antibody fusion proteins selectively bind and eliminate dual antigenexpressing tumor cells. Clin Cancer Res 2016;22:5109-19.

81. Johnson Z, Papaioannou A, Bernard L, Cosimo E, Daubeuf B, et al. Bispecific antibody targeting of CD47/CD19 to promote enhanced phagocytosis of patient B lymphoma cells. J Clin Oncol 2015;33:e14016.

82. Masternak K, Chauchet X, Buatois V, Salgado-Pires S, Shang L, et al. Abstract B37: NI-1701, a bispecific antibody for selective neutralization of CD47 in B cell malignancies. Cancer Immunol Res 2017;5:B37. Available from: http://cancerimmunolres.aacrjournals. org/content/5/3_Supplement/B37.abstract [Last accessed on 8 Apr 2020]

83. Piccione EC, Juarez S, Liu J, Tseng S, Ryan CE, et al. A bispecific antibody targeting CD47 and CD20 selectively binds and eliminates dual antigen expressing lymphoma cells. MAbs 2015;7:946-56.

84. Boyd-Kirkup J, Thakkar D, Brauer P, Zhou J, Chng WJ, et al. HMBD004, a novel anti-CD47xCD33 Bispecific antibody displays potent anti-tumor effects in pre-clinical models of AML. Blood 2017;130:1378.

85. Tahk S, Schmitt S, Augsberger CP, Vick B, Pascual Ponce L, et al. Evaluation of a bifunctional sirp $\alpha$-CD123 fusion antibody for the elimination of acute myeloid leukemia stem cells. Blood 2019;134:2544.

86. de Silva S, Fromm G, Shuptrine CW, Johannes K, Patel A, et al. CD40 enhances type i interferon responses downstream of CD47 blockade, bridging innate and adaptive immunity. Cancer Immunol Res 2019;8:230-45. 
87. Shang L, Buatois V, Hatterer E, Chauchet X, Haddouk H, et al. Abstract 546: Selectively targeting CD47 with bispecific antibody to efficiently eliminate mesothelin-positive solid tumors. Cancer Res 2019;79:546. Available from: http://cancerres.aacrjournals.org/ content/79/13_Supplement/546.abstract [Last accessed on 8 Apr 2020]

88. Cabrales P. RRx-001 acts as a dual small molecule checkpoint inhibitor by downregulating CD47 on cancer cells and SIRP- $\alpha$ on monocytes/macrophages. Transl Oncol 2019;12:626-32.

89. Ramesh A, Kumar S, Nguyen A, Brouillard A, Kulkarni A. Lipid-based phagocytosis nanoenhancer for macrophage immunotherapy. Nanoscale 2020;12:1875-85.

90. Eskiocak U, Guzman W, Daly T, Nelson A, Bakhru P, et al. Abstract 3239: CTX-5861 mediated SIRP $\alpha$ blockade combines with tumor targeting antibodies, checkpoint blockade and/or CD137 agonism to elicit curative anti-tumor activity in syngeneic mouse models. Cancer Res 2019;79:3239. Available from: http://cancerres.aacrjournals.org/content/79/13_Supplement/3239.abstract [Last accessed on 8 Apr 2020]

91. Wang Z, Cao W, Guo T, Zang J. Abstract 5622: A novel immunocytokine fusion protein combining tumor-targeting anti-CD47 antibody with GM-CSF cytokine for enhanced antitumor efficacy. Cancer Res 2018;78:5622. Available from: http://cancerres.aacrjournals.org/ content/78/13_Supplement/5622.abstract [Last accessed on 8 Apr 2020]

92. Ma L, Zhu M, Gai J, Li G, Chang Q, et al. Preclinical development of a novel CD47 nanobody with less toxicity and enhanced anticancer therapeutic potential. J Nanobiotechnology 2020;18:12.

93. Xie YJ, Dougan M, Ingram JR, Pishesha N, Fang T, et al. Improved anti-tumor efficacy of chimeric antigen receptor T cells that secrete single-domain antibody fragments. Cancer Immunol Res 2020;8:518-29.

94. Puro RJ, Bouchlaka MN, Hiebsch RR, Capoccia BJ, Donio MJ, et al. Development of AO-176, a next generation humanized anti-CD47 antibody with novel anti-cancer properties and negligible red blood cell binding. Mol Cancer Ther 2020;19:835-46.

95. Huang Y, Lv S, Liu P, Ye Z, Yang H, et al. A SIRP $\alpha-F c$ fusion protein enhances the antitumor effect of oncolytic adenovirus against ovarian cancer. Mol Oncol 2020;14:657-68.

96. Li Y, Zhang M, Wang X, Liu W, Wang H, et al. Vaccination with CD47 deficient tumor cells elicits an antitumor immune response in mice. Nat Commun 2020;11:581. 